\title{
PROJECT APPLICATION UNTUK SISTEM PEMESANAN DAN PENGIRIMAN BARANG BERBASIS WEB PADA PT. ARAI RUBBER SEAL INDONESIA
}

\author{
Aris Martono ${ }^{1}$, Solehudin ${ }^{2}$, Fajar Januar Eka Putra ${ }^{3}$ \\ Dosen STMIK Raharja Tangerang ${ }^{1}$, Mahasiswa STMIK RAHARJA Tangerang ${ }^{2,3}$ \\ J1. Jenderal Sudirman No. 40, Modernland, Tangerang ${ }^{1,2,3}$ \\ email :aris.martono@raharja.info ${ }^{1}$,solehudin@raharja.info ${ }^{2}$,fajar@raharja.info ${ }^{3}$
}

\begin{abstract}
Abstrak
Perkembangan ilmu pengetahuan dan teknologi saat ini sudah semakin pesat perkembangannya, kebutuhan masyarakatakan akan teknologi informasi semakin meningkat begitu juga dalam dunia bisnis yang cenderung dinamis dan selalu berubah sesuai dengan perkembangan zaman, kebutuhan konsumen, dan lingkungan pemasaran, berakibat pada besarnya permintaan pasar. Disisi lain bermunculan usaha sejenis yang menyebabkan tingginya tingkat persaingan. PT. Arai Rubber Seal Indonesia merupakan salah satu jenis perusahaan yang bergerak di industri komponen spareparts otomotif. Untuk mendukung industri otomotif Perusahaan ini berkembang cukup pesat, dapat dilihat dari pesanan barang yang masuk cukup banyak. Oleh karena itu, perusahaan berusaha untuk meningkatkan kualitas produk-produknya juga meningkatkan sistem informasi pemesanan dan pengiriman barang. Pada perancangan sistem ini penulis menggunakan metode prototype evolutionary karena penulis menginginkan prototype tersebut tetap digunakan untuk iterasi desain berikutnya. Pada sistem ini penulis melakukan metode perancangan menggunakan metode UML (Unified Modeling Language) karena dengan menggunakan metode UML, rekayasa dan pengembangan perangkat dapat dilakukan dengan fokus pengembangan dan desain perangkat lunak itu juga penulis Dengan dilakukannya analisa sistem informasi pemasaran dan pemesanan barang diharapkan dapat memperbaiki aktivitas pemesanan dan pengiriman barang agar dapat bersaing untuk mencapai tujuan perusahaan.
\end{abstract}

Kata Kunci: Pemesanan, Pengiriman Barang, Sistem informasi.

\begin{abstract}
The development of science and technology is now increasingly rapid development, the need masyarakatakan akan information technology is increasing as well in the business world that tend to be dynamic and always changing in accordance with the times, consumer needs, and the marketing environment, resulting in the large market demand. On the other hand emerging similar businesses that cause high levels of competition. PT. Arai Rubber Seal Indonesia is one type of company engaged in automotive spare parts industry. To support the automotive industry The company is growing quite rapidly, can be seen from the order of goods that enter quite a lot. Therefore, the company strives to improve the quality of its products also improve the system of ordering information and delivery of goods. In designing this system the author uses evolutionary prototype method because the author wants the prototype is still used for the next design iteration. In this case, the actual system is seen as an evolution from a very limited initial version to the latest evolution that better than using the author's prototype method also uses the design method. In this system the authors do the design method using UML (Unified Modeling Language) method because by using UML method, engineering and device development can be done with the focus of development and design software it is also author With the analysis of information systems marketing and ordering goods expected to improve the activity Ordering and delivery of goods in order to compete to achieve company goals.
\end{abstract}

Keywords:Booking, Shipping, Information system. 


\section{PENDAHULUAN}

Perkembangan ilmu pengetahuan dan teknologi saat ini sudah semakin pesat perkembangannya, kebutuhan masyarakatakan akan teknologi informasi semakin meningkat. Begitu juga dalam dunia usaha, perusahaan-perusahaan makin dipicu untuk menggunakan teknologi yang baru sebagai alat atau media untuk tetap bertahan dan memenangkan persaingan yang semakin ketat dan keras. Setiap perusahaan harus mampu memanfaatkan dan mengelola data dan informasi perusahaan dengan baik. Pengelolaan yang dulu masih dilakukan secara manual kini mulai berkembang menuju sistem yang terkomputerisasi dengan kompleks dan terintegrasi. Sehingga pengelolaan data dan informasi dapat dilakukan cepat, tepat dan akurat.

Setiap perusahaan ataupun organisasi pasti mempunyai strategi pemesanan yang berbedabeda, karena dengan pemesanan diharapkan dapat meningkatkan profit perusahaan yang diperoleh dari peningkatan di berbagai aspek. Dengan peningkatan profit tersebut perusahaan dapat leluasa melakukan ekspansi bisnis dan membuat usaha semakin berkembang. Begitu juga pada sistem pemesanan barang, perusahaan harus melakukan pengembangan sistem yang lebih efektif dan efisien agar pesanan barang dapat dikelola dengan baik.

PT. Arai Rubber Seal Indonesia merupakan salah satu jenis perusahaan yang bergerak di industri komponen spareparts otomotif. Untuk mendukung industri otomotif. Pada sistem yang sedang berjalan, perusahaan ini masih menggunakan sistem pemesanan dan pengiriman barang yangmasih belum terkomputerisasi dengan baik yaitu dengan pemesanan produk dengan cara customer mengirimkan surat langsung ke Perusahaan untuk pemesanan dan pengiriman barang di PT.Arai Rubber Seal Indonesia.

\section{LANDASAN TEORI}

\subsection{Pengertian prototype}

Menurut Darmawan (2013:229), "Prototype adalah satu versi dari sebuah sistem potensial yang memberikan ide bagi para pengembang dan calon pengguna, bagaimana sistem akan berfungsi dalam bentuk yang telah selesai".

\subsection{Definisi Sistem}

Menurut Rusdiana dan Irfan (2014:28), "Sistem merupakan kumpulan dari beberapa bagian yang memiliki keterkaitan dan saling bekerja sama serta membentuk suatu kesatuan untuk mencapai tujuan dari sistem tersebut".

Menurut Harijono Djojodiharjo dalam buku H.A. Rusdiana dan Moch. Irfan (2014:29), "Sistem adalah kumpulan objek yang mencakup hubungan fungsional antara tiap-tiap objek dengan hubungan ciri setiap objek yang secara keseluruhan merupakan suatu kesatuan secara fungsional".

\subsection{Definisi Pemesanan}

Menurut Sugono Kepala Pusat Bahasa dalam laporan kuliah kerja prakteknya Nina Harfiani (2015/2016:33), "Pengertian pesan adalah suruhan (perintah, nasehat, Permintaan, amanat) yang harus dilakukan atau disampaikan kepada orang lain.

Pesanan adalah permintaan hendak membeli supaya dikirimkan, dibuatkan dan sebagainya. Pemesan/konsumen masa kini menemukan banyak sekali produk dalam setiap kategori. Pemesan memiliki beragam kebutuhan dalam kombinasi serta harga barang/jasa. Harapan pemesan akan mutu dan pelayanan akan semakin tinggi serta terus meningkat. Ditengah pilihan yang paling sesuai dengan kebutuhan serta harapan dan membeli berdasarkan padangan nilai mereka.

Pemesanan tidak hanya dipandangi sebagai satu bagian. Bagian penjualan terlibat dalam mengambil keputusan manajemen sebelum produksi dirancang sampai terjual. Perusahaanperusahaan unggulan masa kini beralih dari memandang perusahaan sebagai kumpulan 
bagian-bagian menjadi suatu sistem untuk mengelola dan menguasi proses ini seperti penciptaan pemesanan dan pemenuhan pesanan. Setiap proses meliputi beberapa langkah dan memerlukan masukan dari beberapa bagian produksi, keuangan dan manager.

Barang/produk adalah suatu sifat yang komplek baik dapat diraba maupun tidak dapat di raba, termasuk bungkus, harga, prestise perusahaan dan pengecer. Pelayanan perusahaan dan pengecer, yang diterima oleh pembeli untuk memuaskan keinginan atau kebutuhan. Penggolongan menurut tingkat pemakaian dan kekongkritanya:

1. Barang Tahan lama (durable Goods) adalah barang-barang yang secara normal dapat dipakai berkali-kali, jadi dapat dipakai untuk jangka waktu yang relative lama.

2. Barang Tidak Tahan Lama (non durable goods) adalah barang-barang yang secara normal hanya dipakai satu kali atau beberapa kali saja, artinya sekali barang itu dipakai akan habis, rusak, atau tidak dapat dipakai lagi.

\subsection{Definisi Pengiriman Barang}

Secara umum pengiriman adalah segala upaya yang di selenggarakan secara sendiri atau bersama-sama dalam suatu organisasi untuk memberikan pelayanan jasa berupa pengiriman barang.

\subsection{Permasalahan}

Berdasarkan latar belakang telah dijelaskan pada uraian sebelumnya, penelitian ini ada kaitannya dengan sistem pemesanan dan pengiriman barang pada PT. Arai Rubber Seal Indonesia. Ada beberapa hasil analisa yang akan dijelaskan mengenai sistem informasi pemesanan dan pengiriman barang yang sedang berjalan pada perusahaan tersebut. Oleh karena itu penulis mengambil beberapa pokok permasalahan sebagai berikut :

1. Bagaimana sistem pemesanan dan pengiriman barang yang sedang berjalan pada PT. Arai Rubber Seal Indonesia?

2. Apakah kendala yang dialami PT. Arai Rubber Seal Indonesia pada penggunaan sistem pemesanan dan pengiriman barang selama ini?

3. Apakah penggunaan sistem pemesanan dan pengirirman barang yang sedang berjalan sudah efektif dan efisien?

\subsection{Literature Review}

Literature review atau tinjauan pustaka adalah kumpulan teks yang bertujuan untuk meninjau titik-titik saat ini pengetahuan dan atau pendekatan metodologis pada topik tertentu. Tinjauan literatur adalah sumber-sumber sekunder, dan dengan demikian, tikak melaporkan setiap eksperimental asli baru atau bekerja. Paling sering dikaitkan dengan literatur berorientasi akademis, seperti tesis, tinjauan pustaka biasanya mendahului sebuah proposal dan hasil penelitian bagian. Tujuan utamanya adalah untuk membawa pembaca up to date dengan literatur saat ini pada topik dan membentuk dasar untuk tujuan lain, seperti tujuan masa depan yang mungkin dibutuhkan di daerah tersebut. Terstruktur dengan baik tinjauan literatur dicirikan oleh aliran ide yang logis saat ini dan reverensi yang relevan dan konsisten, referensi yang sesuai dengan gaya penggunaan teknologi yang tepat dan yang tidak bisa dan daa pandangan yang komprehensif tentang penelitian sebelumnya mengenai topik ini.

Banyak penelitian yang sebelumnya dilakukan mengenai sistem informasi kependudukan dan penelitian lain yang bersangkutan. Dalam upaya mengembangkan dan menyempurnakaan sistem informasi kependudukan ini perlu dilakukan study pustaka (literature review) sebagai salah satu dari penerapan metode penelitian yang akan dilakukan, diantaranya sebagai berikut:

1. Penelitiaan yang dilakukan oleh Hanung Arif Pamungkas pada tahun 2011, STIMIK

AMIKOM yogyakarta. Dengan judul "Analisa dan perancangan sisem informasi pemesanan pada konveksi Seize The Day T-shirting The World Yogyakarta". Pada 
penelitian ini menjelaskan bahwa Konveksi Seize The Day dalam melakukan pengolahan data pemesanan saat ini masih menggunakan sistem manual, sehingga pelaksanaannya masih terdapat kendala. Kendala yang timbul misalnya dari segi pencatatan dan waktu dalam pemesanan yang secara tidak langsung mengurangi kualitas informasi yang seharusnya lebih akurat, relevan dan tepat waktu dalam proses operasional. Tujuan dari penelitian ini adalah peneliti mengusulkan rancangan sistem baru yang diharapkan mampu memberikan kemudahan dalam pencatatan data transaksi serta bisa meningkatkan pelayanan dan produktifitas kerja. Konveksi Seize The Day perlu mengadakan perubahan dalam hal pengolahan data pemesanan dari sistem manual menjadi sistem terkomputerisasi, sehingga menjadi lebih praktis, cepat dan mudah dalam menyajikan laporan sehingga dalam proses pengambilan keputusan lebih cepat.

2. Tinjauan studi dari penelitian viktor Nicolas Nore, TA 2013, Universitas widyatmaja Bandung dengan judul "Perancangan Sistem Informasi Penjualan Pemesanan Produk Berbasis Web di CV. Richness Development Bandung". Pada enelitian ini menjelaskan bahwa dalam melakukan kegiatannya perusahaan ini masih menggunakan proses konvensional pada saat konsumen ingin memesan produk dan rincian pesanannya melalui email kepada pihak perusahaan. Kendala yang timbul adalah pengiriman informasi melalui email seringkali menimbulkan masalah karena format informasi pemesanan seperti desain dan rincian pesanan yang di kirimkan oleh konsumen sering tidak sesuai dengan kebutuhan informasi perusahaan untuk pembuatan barang yang dipesan. Hal ini mengakibatkan proses transaksi berulang-ulang dan membutuhkan waktu yang lama. Tujuan dari penelitian ini adalah peneliti ingin membangun sistem informasi penjualan dan pemesanan berbasis web pada CV. Richness Development sehingga memudahkan konsumen melakukan pesanan dan media informasi penjualan peroduk akan lebih komunikatif dan informatif untuk promosi produk secara detail.

3. Penelitian yang dilakukan oleh Rilyasari Melia Prastiwi pada tahun 2014, STMIK

Raharja Tangerang, dengan judul "Perancangan Sistem Informasi pemasaran pada Website CV. Febulous Store". Pada penelitian ini menjelaskan bahwa CV. Fabulous Store merupakan perusahaan yang bergerak dibidang konveksi pakaian dan aksesoris. Perusahaan ini menggunakan sistem pemasaran yang masih bersifat manual yaitu customer datang langsung untuk bertannya mengenai produk. Hal tersebut menyebabkan ketidakpuasan customer terhadap layanan dan dampak terhadap adanya indikasi omset penjualan yang menurun. Oleh karena itu, penelitian ingin mengembangkan sistem informasi pemasaran menjadi berbasis web agar perusahaan dapat menyajikan informasi dengan mudah, cepat, tepat, akurat dan memuaskan bagi customer.

\section{HASIL DAN PEMBAHASAN}

Setelah meneliti dan mengamati beberapa permasalahan yang terjadi di dalam sistem pemesanan dan pengiriman barang yang berjalan di PT. Arai Rubber Seal Indonesia penulis memberikan beberapa alternatif pemecahan masalah yang dihadapi sistem yang berjalan yaitu

Memanfaatkan Teknologi Informasi yang berbasis internet dengan membuat website sesuai dengan kebutuhan customer untuk menunjang sistem pemesanan dan pengiriman barang dan menyebarkan informasi secara lebih luas mengenai berbagai macam produk yang ditawarkan dan meliputi adanya latar belakang perusahaan, kegiatan perusahaan, pemesanan barang dan pembayaran.

Pada pembuatan website tersebut harus memperhatikan pengembangan sistem informasi pemasaran dan pemesanan barang yang tersedia di website tersebut dan memberikan kemudahan pada customer dalam menyediakan transaksi pemesanan barang dan pembayaran secara online sehingga proses transaksi dapat dilakukan secara efektif dan customer dapat 
secara langsung berinteraksi dengan sistem sesuai dengan kebutuhan. Tersedia juga kolom bantuan dan penanganan keluhan pelanggan agar pihak perusahaan dapat menindaklanjuti dan menangani keluhan pelanggan dengan cepat.

Website tersebut juga dibuat untuk perusahaan itu sendiri agar user mendapatkan kemudahan dalam proses pengolahan data dan laporan yang dibutuhkan oleh pimpinan atas transaksi penjualan, bahkan pimpinan dapat secara langsung mengontrol volume penjualan dan tingkat kepuasaan konsumen terhadap barang yang diproduksi.

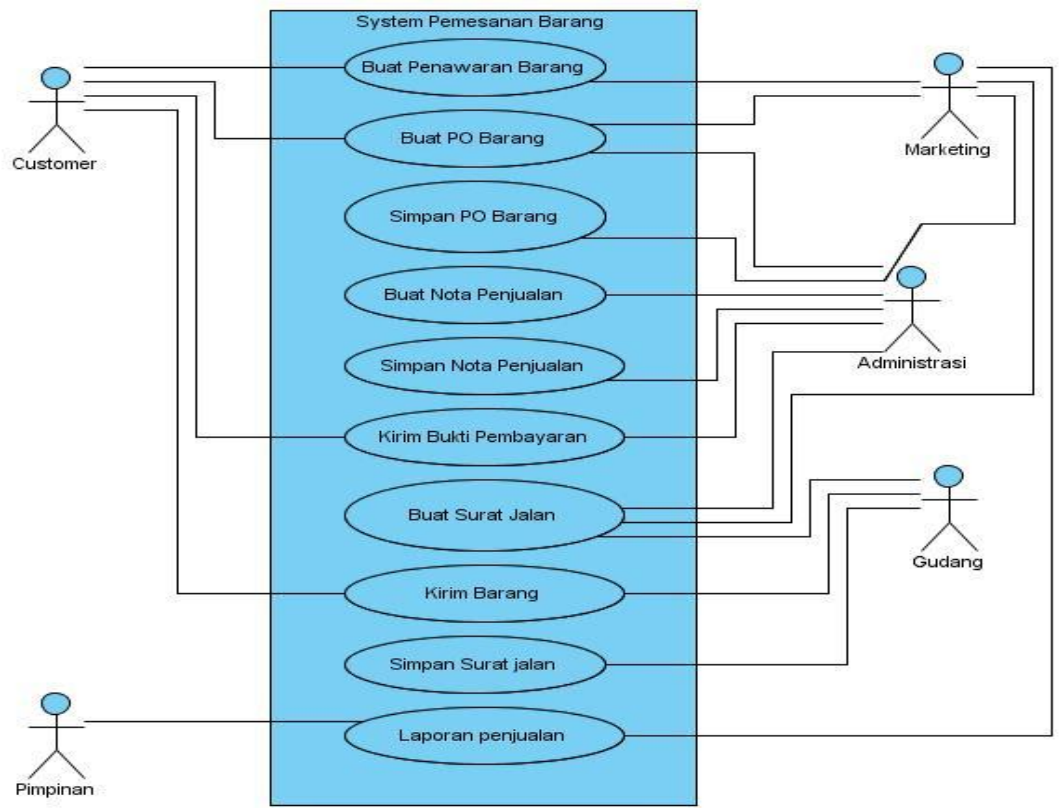

Gambar 1. Use Case Diagram Pemesanan Barang

Berdasarkan Gambar Use Case Diagram sistem Pemesanan Barang diatas terdapat:

1. 1 system yang mencakup seluruh pengolahan data.

2. 5 actor yang melakukan kegiatan yaitu: Customer, Marketing, Administrasi, Gudang, Pimpinan.

3. 2 collaboration yang menggambarka Pemesanan Barang.

4. 10 use case yang dilakukan diantaranya: Membuat Penawaran Barang, Membuat PO Barang, Menyimpan PO Barang, Buat Nota Penjualan, Kirim Bukti Pembayaran, Buat Surat jalan, Kirim Barang, Simpan Surat Jalan, Laporan Penjualan.

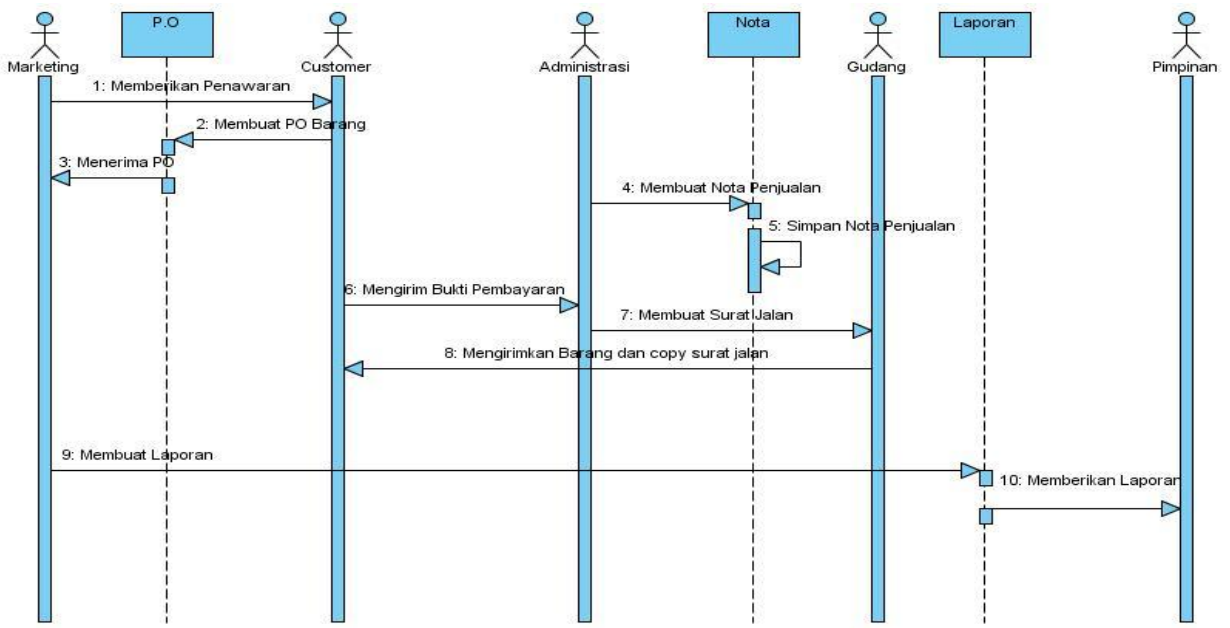

Gambar 2. Sequence Diagram Pemesanan Barang 
Berdasarkan Gambar sequence diagram sistem Pemesanan terdapat:

1. 5 actor yang melakukan kegiatan, yaitu: Marketing, Customer, Administrasi, Gudang dan Pimpinan.

2. 3 Lifeline objek entity antar muka yang saling beirnteraksi, yaitu Purchase Order, Nota, dan Laporan.

3. 10 Message, yang memuat informasi-informasi tentang aktifitas yang dapat dilakukan oleh actor tersebut:

Berikut Gambar Perancangan Menggunakan Metode Prototype

1. Prototype Tampilan Halaman Login

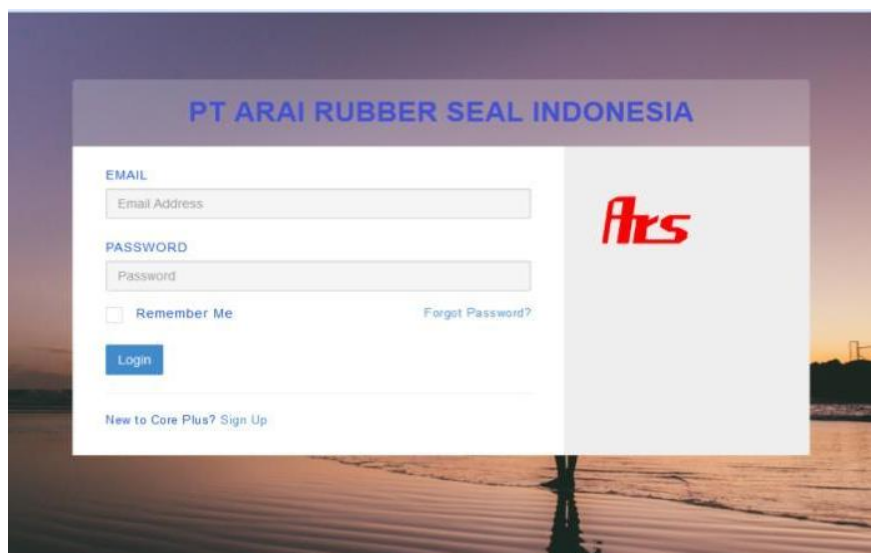

Gambar 2. Tampilan Halaman Login

Halaman login merupakan tampilan awal tampil ketika user menjalankan sistem ini. Pada halaman ini user diminta untuk memasukkan username, password agar dapat mengakses sistem tersebut.

\section{Prototype Tampilan Halaman Utama}

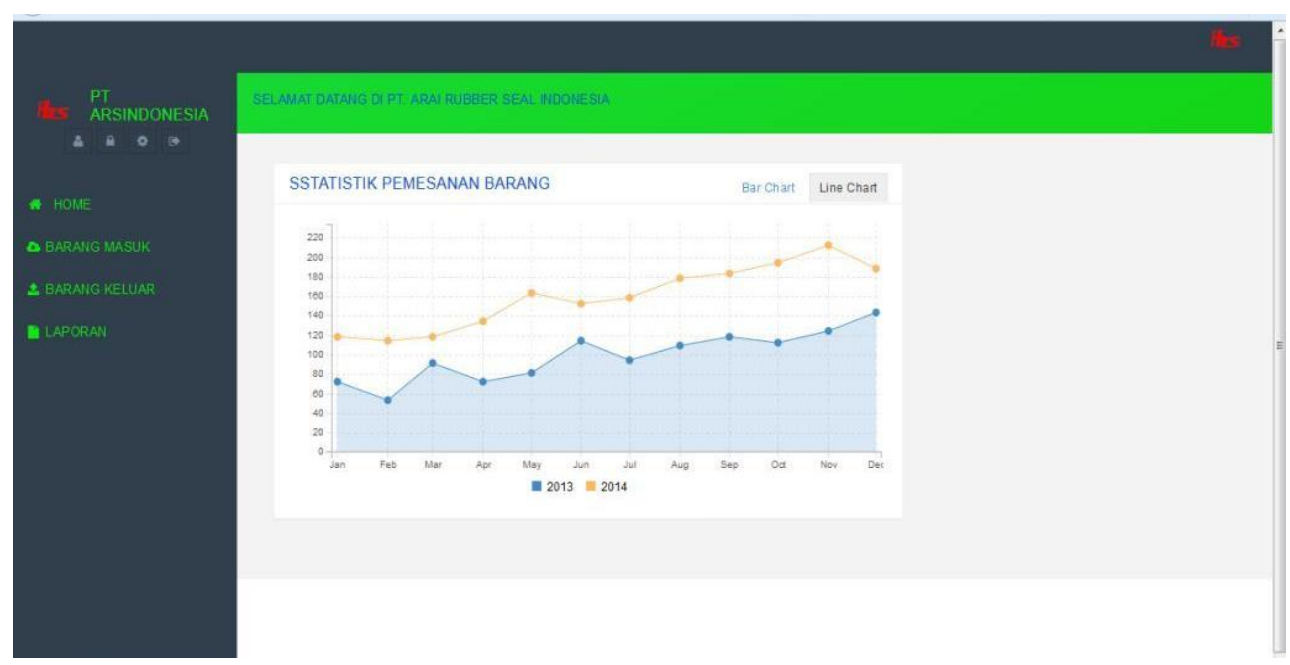

Gambar 3. Prototype Tampilan Halaman Utama

Halaman Utama adalah tampilan menu setelah user melakukan login pada form login. Pada halaman ini user dapat mengakses atau memilih macam-macam menu pada sistem ini. 
3. Prototype Tampilan Halaman Data Pemesanan

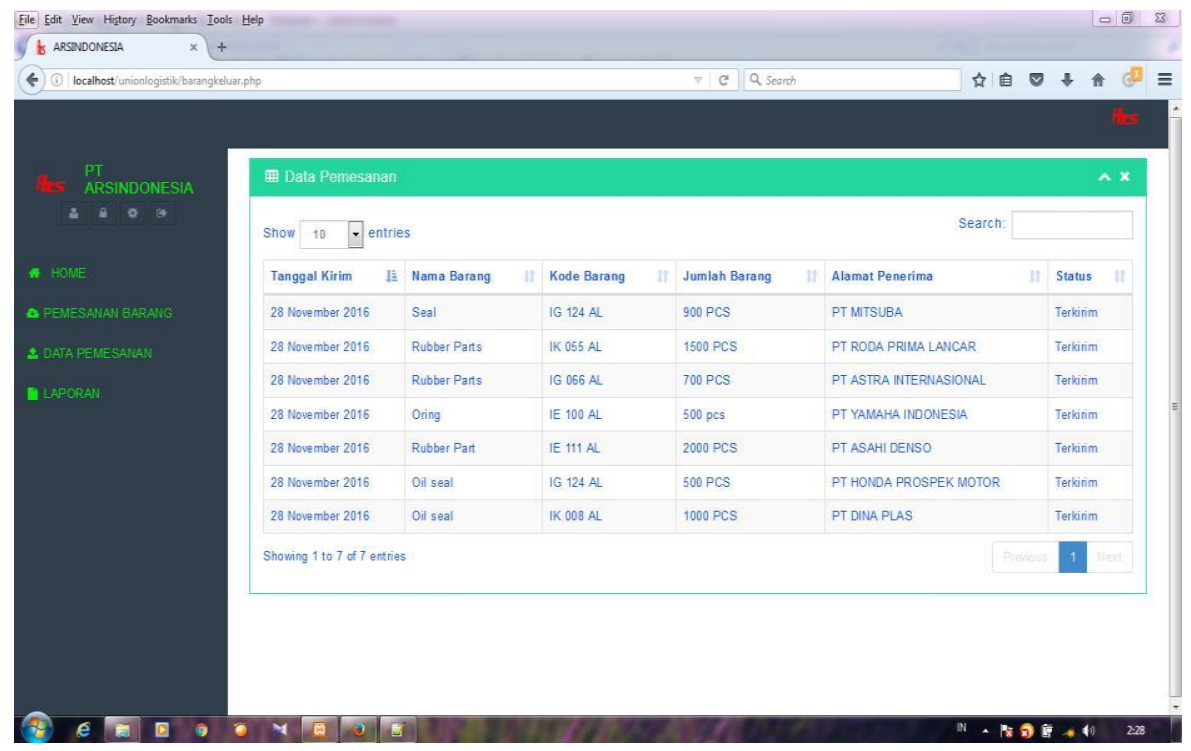

Gambar 4. Prototype Tampilan Halaman Data Pemesanan

Pada form halaman ini akan menampilkan semua data pemesanan dari pelanggan. Terdapat 6 kategori pada tabel pemesanan , tanggal kirim, nama barang, kode barang, jumlah pemesanan, alamat pemesanan, dan table status.

4. Prototype Tampilan Halaman Form Pemesanan

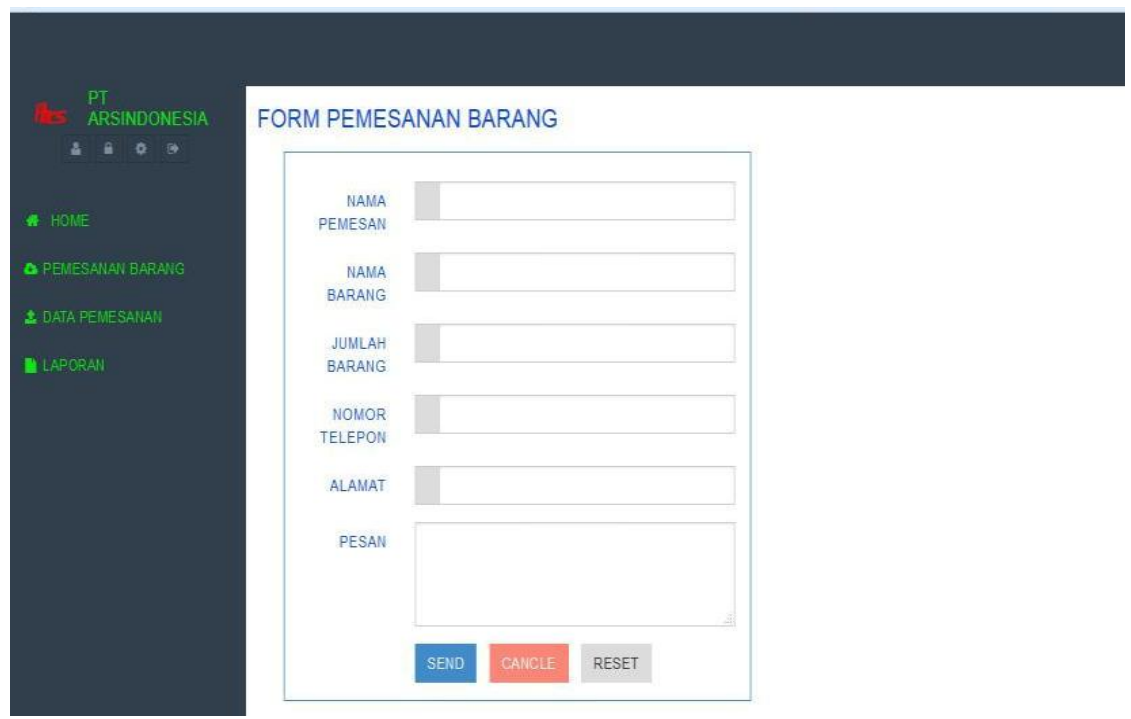

Gambar 5 Prototype Tampilan Halaman Form Pemesanan

Pada form halaman pemesanan barang customer bisa langsung melakukan pemesanan sesusi dengan table pemesanan barang yang meliputi nama pemesanan, nama barang, jumlah barang, nomor telepon, alamat, dan pesan. 
5. Prototype Tampilan Halaman Laporan

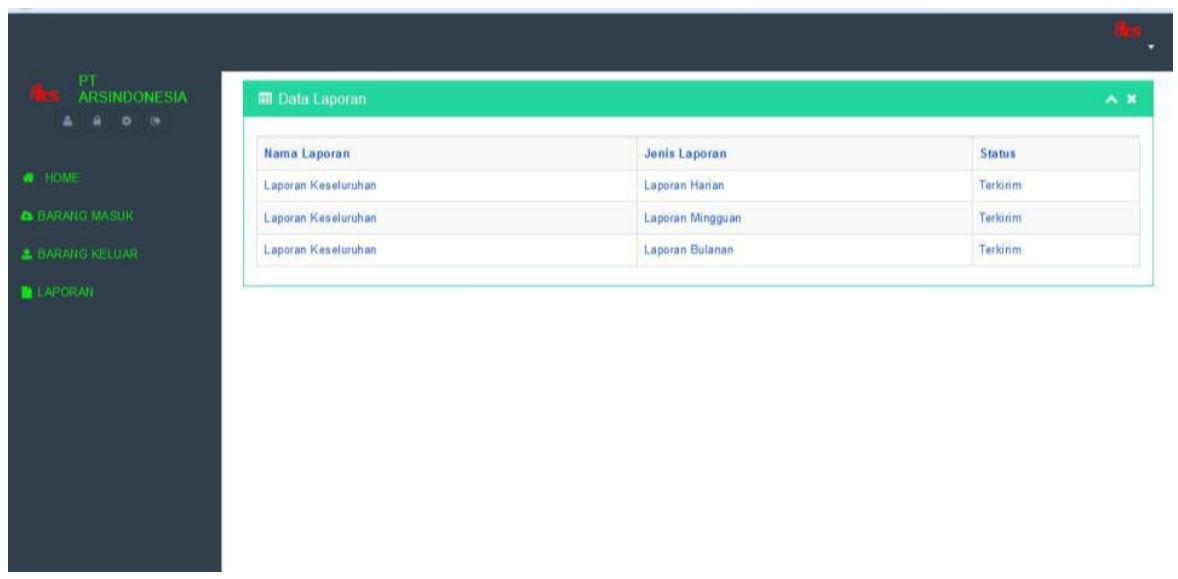

Gambar 6. Prototype Tampilan Halaman Laporan

Pada form halaman ini akan menampilkan semua jenis laporan pemesanan dari pelanggan. Terdapat 3 kategori pada tabel laporan, data laporan, jenis laporan, dan table status.

\section{KESIMPULAN DAN SARAN}

Berdasarkan pembahasan yang telah dijelaskan pada bab sebelumnya perihal laporan tentang "Project Application Untuk Sistem Pemesanan Dan Pengiriman Barang Berbasis Web Pada PT. Arai Rubber Seal Indonesia" berdasarkan rumusan masalah dapat ditarik kesimpulan sebagai berikut:

1. Sistem Informasi Pemesanan dan pengiriman Barang pada PT. Arai Rubber Seal Indonesia saat ini cenderung kurang mengikuti perkembangan teknologi informasi.

2. Sistem Informasi Pemasaran pada PT. Arai Rubber Seal Indonesia masih menggunakan metode konvensional yaitu dengan menggunakan katalog produk dan memberikan sampel barang jadi sehingga lebih memboroskan sumber daya dan kurang efisien juga pada proses pengolahan data antar bagian masih menggunakan cara manual melalui proses pencatatan.

3. Sistem Informasi Pemesanan Dan Pengiriman Barang pada PT. Arai Rubber Seal Indonesia masih kurang efektif yaitu dilakukan secara manual sehingga memerlukan proses waktu yang panjang mulai dari customer datang langsung ke perusahaan, penjelasan informasi seputar produk oleh Bagian Penjualan, Customer memesan produk, membuat surat pesanan barang, produk dikirim ke alamat customer, transaksi pembayaran, sampai pembuatan laporan ke pimpinan.

\section{DAFTAR PUSTAKA}

[1]. Darmawan, Deni. 2013. Sistem Informasi Manajemen. Bandung: PT Remaja Rosdakarya Offset.

[2]. H.A. Rusdiana dan Moch. Irfpan. 2014. "Sistem Informasi Manajemen”.Cetakan ke1,Bandung:CV PUSTAKA SETIA

[3]. Nore, Victor Nicolas. 2013. Perancangan Sistem Informasi Penjualan Pemesanan Produk Berbasis Web di CV. Richness Development Bandung. Tugas Akhir. Bandung : Universitas Widyatama Bandung.

[4]. Pamungkas, Hanung Arif. 2011. Analisis dan Perancangan Sistem Informasi Pemesanan pada Konveksi Seize The Day T-shirting The World Yogyakarta. Yogyakarta : STMIK AMIKOM Yogyakarta. 
[5]. Prastiwi, Rilyasari Melia. 2015. Perancangan Sistem Informasi Pemasaran pada Website CV. Fabulous Store. Laporan KKP. STMIK Raharja. 